\title{
A modified tetrazolium reaction for identifying malignant cells from gastric and colonic cancer
}

\author{
KS IBRAHIM, OAN HUSAIN, L BITENSKY*, J CHAYEN* \\ From the Cytology Department, Charing Cross Hospital, London W6 8RF and the * Division of Cellular \\ Biology, Kennedy Institute of Rheumatology, London W6 7DW
}

SUMMARY When non-malignant cells were reacted for glucose-6-phosphate dehydrogenase activity, with neotetrazolium chloride as the indicator of the activity, oxygen competed with the neotetrazolium and nullified the reaction. In contrast, about $30 \%$ of the activity was retained in malignant cells, in sections and in smears, from cancer of the stomach or colon. This could provide the basis of a qualitative (black-or-white) functional test for distinguishing malignant cells in these conditions.

The need for functional, clear-cut, tests to complement conventional cytological screening led us to reinvestigate the activities associated with glucose-6-phosphate dehydrogenase (G6PD) in malignant cells, derived from the stomach and from the colon. This enzyme is the regulatory enzyme ${ }^{1}$ of the pentose phosphate shunt which provides ribose for the synthesis of nucleic acids and NADPH for biosynthetic mechanisms; ${ }^{2}$ for these reasons, ${ }^{3}$ it has been much studied in relation to malignancy..$^{4-12}$ Although such studies had indicated that, under certain conditions, G6PD activity could be used to detect malignant cells, ${ }^{13}$ they have not yielded a clear and reliable diagnostic test.

In the present study we have considered the possibility, indicated by previous investigations, ${ }^{4} 1012$ that malignant cells may possess a peculiar property that can influence the cytochemical demonstration of G6PD activity. In normal cells, this activity can be demonstrated by reacting the cells with optimal concentrations of substrate; coenzyme (NADP); and an intermediate hydrogen-carrier, phenazine methosulphate (PMS) that transfers reducing equivalents quantitatively from the NADPH, generated by the oxidative activity of the enzyme, direct to a tetrazolium salt that acts as the terminal hydrogen-acceptor. On reduction, the relatively colourless tetrazolium salt is converted into a strongly coloured, insoluble formazan. Neotetrazolium chloride can be used as the terminal hydrogenacceptor provided that the reaction is done in an atmosphere of nitrogen, to exclude oxygen which competes with neotetrazolium chloride for the

Accepted for publication 11 August 1982 reducing equivalents. However there were indications $^{41012}$ that the ability of oxygen to compete in this way was diminished in malignant cells. It was therefore decided to optimise the cytochemical method for demonstrating G6PD activity in malignant cells, and to examine whether this relative "oxygen insensitivity" of the cytochemical reaction, when done on malignant cells, could be developed into a cytological "stain" for malignant cells.

\section{Material and methods}

The gastric material was studied either as cryostat sections or as smears. Biopsies were obtained from 17 malignant and 18 non-malignant cases. The malignant cases included 13 adenocarcinoma and four squamous cell carcinoma from the lower end of the oesophagus. The non-malignant specimens were obtained from seven normal cases, five cases with gastric ulcer and six with gastritis. The biopsies were obtained either through a gastroscope (23 cases) or from resected specimens ( 12 cases).

Air-dried smears were obtained from 18 malignant and 15 non-malignant cases. The malignant specimens included 16 adenocarcinoma and two squamous cell carcinoma. The non-malignant cases included six with apparently normal stomachs; four with gastritis; and five with gastric ulcer. Materials studied as smears were obtained either through a gastroscope (29 cases) or by scraping a resected specimen with a spatula (four specimens).

Colonic samples were studied only in cryostat sections. Biopsies were obtained from nine adenocarcinomata and eight normal mucosae. The biopsies of the malignant cases were obtained from 
resected specimens. Normal mucosa was obtained either from the resected specimens away from the tumour site (in six cases) or through a fibro-optic colonoscope (in two cases).

The final diagnosis was made by histological examination of the resected specimen or of the endoscopic biopsy obtained at the same time that the samples were collected except in normal cases where the diagnosis was obvious by gastroscopy. Brush samples were also collected for standard cytological examination whenever brush material was used for these studies.

Biopsies were chilled in hexane at $-70^{\circ} \mathrm{C}$ and sectioned at $18 \mu \mathrm{m}$ in a Bright's cryostat fitted with an automatic drive to produce sections of constant thickness. The cabinet temperature was $-25^{\circ} \mathrm{C}$; the knife was cooled to $-70^{\circ} \mathrm{C}$ with solid carbon dioxide.$^{14}$ Cells collected by a brush, or spatula, were spread on to albuminised slides and dried in air.

The normal cytochemical reaction-medium ${ }^{14}$ was modified to give maximal G6PD activity in the malignant cells. It consisted of: chloroform-purified neotetrazolium chloride ( $5 \mathrm{mmol} / \mathrm{l}$; Serva); glucose6-phosphate disodium salt ( $5 \mathrm{mmol} / \mathrm{l}$; Boehringer); $\mathrm{NADP}^{+}(3 \mathrm{mmol} / \mathrm{l}$; Boehringer $) ; \mathrm{PMS}(0.67 \mathrm{mmol} / \mathrm{l}$; Sigma); in $0.05 \mathrm{~mol}$ glycyl glycine buffer, $\mathrm{pH} 8.0$, containing $34 \mathrm{mmol} / \mathrm{l}$ calcium chloride and $40 \%$ (wt/ vol) Polypep 5115 (Sigma) to stabilise the cells in sections or in smears. Two aliquots of this medium were prepared: one was saturated with oxygen and the other with nitrogen. A Perspex ring was placed ${ }^{14}$ around the section or smear and was filled with the reaction-medium at $37^{\circ} \mathrm{C}$. The reaction was performed in an atmosphere of oxygen or nitrogen, as appropriate. At the end of the incubation period (5 min in nitrogen; $30 \mathrm{~min}$ in oxygen) the slides were washed in warm distilled water, dried, and mounted in Farrant's medium. The coloured reaction-product was measured at $585 \mathrm{~nm}^{15}$ by means of a Vickers M85 scanning and integrating microdensitometer ${ }^{16}(\times 40$ objective; scanning spot of $0.5 \mu \mathrm{m}$ diameter in the plane of the specimen). Normally 20 cells in each of two duplicate sections or smears were measured.

\section{Results}

The reaction appeared to be specific in that omission of either the substrate or coenzyme from the reaction-medium reduced the apparent activity to unmeasurable levels. The linearity of reaction with time of reaction, both in nitrogen and in oxygen, was is established in sections of three malignant gastric specimens and two colonic carcinomata. Thus it was legitimate to compare the activities per unit time, under these two conditions, where very different times of reaction were required for precise measurement.

The activity of the mucosal cells in sections of $i$ stomach and in sections of gastric cancer was very $\vec{\omega}$ similar when the reactions were done in an atmosphere of nitrogen (Table). Thus the actual $\frac{\circ}{J}$ G6PD activity in these cells was virtually identical. $\vec{T}$ The same was true when gastric mucosal cells, $\mathbb{D}$ derived from benign or from malignant cases, were studied in smears, or in sections of benign or $\stackrel{\equiv}{2}$ malignant conditions of the colon (Table). However, in cells from benign conditions, there was almost no $\stackrel{\infty}{\infty}$ colouration when the reaction was done in an atmosphere of oxygen, even for $30 \mathrm{~min}$ as against the $5 \mathrm{~min}$ required for a strong reaction in an atmosphere of nitrogen. When the activities measured were divided by the incubation-time, to give the activity

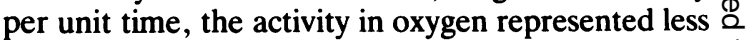
than $1 \%$ of that found in the absence of oxygen $(\% \overrightarrow{\overrightarrow{0}}$ residual activity: Table). In contrast, over $20 \% \frac{3}{3}$ residual activity was found in the malignant cells. Consequently, with the prolonged incubation-time of $30 \mathrm{~min}$, the malignant cells appeared to be as strongly coloured, or even more strongly coloured, than they had been when incubated for $5 \mathrm{~min}$ in nitrogen; the benign cells looked virtually colourless.

In considering the individual results, the activities measured in nitrogen in sections of individual o specimens showed complete overlap between the benign and malignant gastric specimens. In contrast, 을 the activities measured in oxygen showed no overlap, the values for the benign specimens all being less than $\sigma$

Glucose-6-phosphate dehydrogenase (G6PD) activity (mean relative absorption $\pm S E M$ ) in sections of gastric and colonic mucosa and gastric smears measured in the presence of nitrogen (5 min reaction) or of oxygen (30 min reaction)

\begin{tabular}{|c|c|c|c|c|c|c|}
\hline \multirow[t]{2}{*}{ Site } & \multirow[t]{2}{*}{ Condition } & \multirow[t]{2}{*}{ Specimen } & \multirow[t]{2}{*}{ No of specimens } & \multicolumn{2}{|c|}{ G6PD activity in } & \multirow[t]{2}{*}{ \% residual activity } \\
\hline & & & & $N_{2}$ & $\mathrm{O}_{2}$ & \\
\hline \multirow[t]{2}{*}{ Stomach } & Benign & Sections & 18 & $284 \pm 24$ & $17 \cdot 4 \pm 47$ & 0.01 \\
\hline & Malignant & Sections & 17 & $225 \pm 16$ & $410 \pm 38^{*}$ & $26 \cdot 8$ \\
\hline \multirow[t]{2}{*}{ Stomach } & Benign & Smears & 15 & $176 \pm 16$ & $18 \cdot 6 \pm 12 \cdot 3$ & 0.02 \\
\hline & Malignant & Smears & 18 & $176 \pm 12$ & $328 \pm 34^{*}$ & $31 \cdot 0$ \\
\hline \multirow[t]{2}{*}{ Colon } & Benign & Sections & 8 & $235 \pm 12 \cdot 8$ & $8 \cdot 3 \pm 3 \cdot 2$ & 0.58 \\
\hline & Malignant & Sections & 9 & $265 \pm 20$ & $355 \pm 42^{*}$ & $22 \cdot 3$ \\
\hline
\end{tabular}

${ }^{*} \mathrm{p}<0 \cdot 001$ (comparison of activities in oxygen of benign and of malignant cells; Student's $t$ test). 
100 units of relative absorption (Figure). The same was true for smears derived from benign and malignant conditions of the stomach except for one case. This was from a patient with a large and persistent gastric ulcer.

In sections from one case of colonic carcinoma, stained with haematoxylin and-eosin, a benign adenoma was found together with microfoci of carcinoma. In serial sections, although both benign and malignant cells were strongly coloured after the G6PD reaction, done in nitrogen, only the carcinomatous microfoci were coloured when the reaction was done in oxygen.

\section{Discussion}

The amount of G6PD activity, as measured in an atmosphere of nitrogen, was very similar in both the benign and the malignant cells. However the apparent activity, measured in an atmosphere of oxygen, was strikingly dissimilar. Since the activities were linear with time of reaction, it was possible to extrapolate the results obtained after $30 \mathrm{~min}$ in oxygen to the results that would have been obtained, were they measurable, at 1 or $5 \mathrm{~min}$. In this way it was possible to calculate that the apparent activity of the

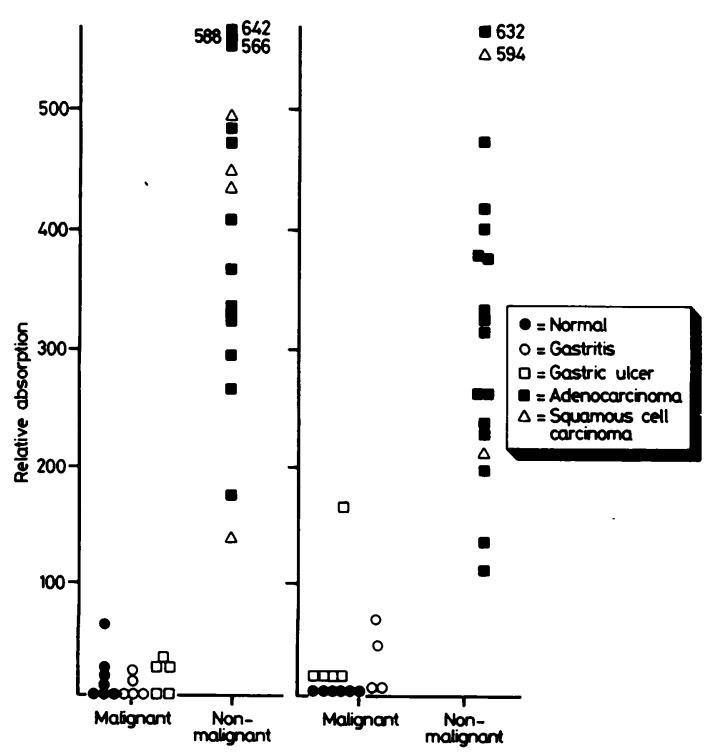

Residual glucose-6-phosphate dehydrogenase activity (mean relative absorption of 40 cells/sample) demonstrated in an atmosphere of oxygen. Left hand columns-measured in sections of gastric specimens. Right hand columnsmeasured in smears from gastric mucosa. benign cells, in oxygen, was less than $1 \%$ of that obtained in nitrogen; that of the malignant cells was $20-30 \%$ of what was found in nitrogen (Table).

It should be emphasised that these results do not mean that oxygen inhibits the enzyme. They imply only that in the benign cells, oxygen preferentially reacted with the reducing equivalents derived from NADPH, and carried by PMS; consequently the colouration of the cells, by formazan, was decreased to virtually negligible amounts. This was expected: it is because of this effect that dehydrogenase activity is normally tested with a tetrazolium salt of more negative electrode potential than neotetrazolium chloride, since such tetrazolium salts are relatively unaffected by the presence of oxygen. ${ }^{17}$ It is less clear why this competition, between oxygen and neotetrazolium chloride, was considerably less in the malignant cells. It seems likely to be caused by some mechanism, operating in the malignant cells, that effectively excludes the effects of oxygen. Thus these results may be analogous to those found in electron spin resonance studies ${ }^{18}$ in which benign tissue, exposed to oxygen, produced signals indicative of the formation of free radicals whereas malignant tissue did not.

Technical worries ${ }^{12}$ concerning the demonstration of this apparent "oxygen-insensitivity" of malignant cells seem to have been overcome by the modifications made in the reaction-medium used in the present study. Thus with Polypep 5115, a partially degraded collagen, as the stabiliser of the sections, and with a relatively high concentration of calcium in the reaction-medium, there was no apparent loss of formazan from the sections.

Although the mechanism, by which the effects of oxygen are partially excluded from the cytochemical reaction in malignant cells, is not known, the test significantly differentiated between benign and malignant cells (Table). When malignant and benign cells were incubated in this reaction-medium, in an atmosphere of oxygen, the former were well stained and the latter were hardly coloured. Thus it is possible that this test may form a functional adjunct to histological and cytological diagnosis of malignancy, at least in these types of cancer, and could lend itself to a degree of automation by providing a much stronger detector signal than is present in cellular material that is simply stained with the dyes currently in use.

\footnotetext{
References

' Krebs HA, Eggleston LV. The regulation of the pentose phosphate cycle in rat liver. Adv Enzyme Regul 1974;24:422-34.

${ }^{2}$ Chayen J, Altman FP, Butcher RG. The effect of certain drugs on the production and possible utilisation of reducing equivalents
} 
outside the mitochondria. In: Dikstein S, ed. Fundamentals of cell pharmacology. Springfield: Thomas, 1973:196-230.

${ }^{3}$ Weber G. Enzymology of cancer cells. $N$ Engl $J$ Med 1977;296:486-93; 541-51.

4 Chayen J, Bitensky L, Aves EK, Jones GRN, Silcox AA, Cunningham GJ. Histochemical demonstration of phosphogluconate dehydrogenase in proliferating and malignant cells. Nature 1962;195:714-5.

${ }^{5}$ Bonham DG, Gibbs DF. A new enzyme test for gynaecological cancer. 6-phosphogluconate dehydrogenase activity in vaginal fluid. $\mathrm{Br}$ Med J 1962;ii:823-4.

- Cohen RB. Glucose 6-phosphate dehydrogenase activity in hyperplastic and neoplastic lesions of the breast. A histochemical study. Cancer 1964;17:1067-1072.

${ }^{7}$ Cameron CB, Husain OAN. 6-phosphogluconate dehydrogenase activity in vaginal fluid: limitations as a screening test for genital cancer. Br Med J 1965; i: 1529-30.

${ }^{*}$ Cohen HJ, Elizalde A, Miller SP. Cytologic studies of glucose 6-phosphate dehydrogenase in malignancy. Cancer 1968;21:1055-60.

${ }^{9}$ Diengdoh JV, Chayen J. A histochemical study of experimentally induced malignant skin tumours. BrJ Dermatol 1969;81:835-49.

${ }^{10}$ Altman FP, Bitensky L, Butcher RG, Chayen J. Integrated cellular chemistry applied to malignant cells. In: Evans DMD. ed. Cytology automation. Edinburgh: Livingstone, 1970:82-99.

" Heyden G. Enzymatic changes associated with malignancy with special reference to aberrant'G-6-PD activity. In: Pattison JR, Bitensky L, Chayen J, eds. Quantitative cytochemistry and its applications. London and New York: Academic Press, 1979:253-9.
12 Butcher RG. The oxygen insensitivity phenomenon as a diagnostic aid in carcinoma of the bronchus. In: Pattison JR, Bitensky L, Chayen J, eds. Quantitative cytochemistry and its applications. London and New York: Academic Press, 1979:241-51.

${ }^{13}$ Gibbs DF, Labrum AH, Stagg BH. Vaginal fluid enzymology. A new assay method with enzyme/potassium ratios. Am J Obstet Gynecol 1968;102:982-8.

${ }^{14}$ Chayen J, Bitensky L, Butcher RG. Practical histochemistry. London, New York: Wiley, 1973.

${ }^{15}$ Butcher RG, Altman FP. Studies on the reduction of tetrazolium salts. II. The measurement of the half-reduced and fully reduced formazans of neotetrazolium chloride in tissue sections. Histochemie 1973;37:351-63.

${ }^{16}$ Bitensky L. Microdensitometry. In: Evered D, O'Connor M, eds. Trends in enzyme histochemistry and cytochemistry. Ciba Found Symp 1980;73:181-202. Excerpta Medica, Amsterdam.

${ }^{17}$ Altman FP. Quantitative dehydrogenase histochemistry with special reference to the pentose shunt dehydrogenases. Progr Histochem Cytochem 1972;4:225-73.

${ }^{18}$ Slater TF, Crook JWR. Electron spin resonance studies on normal and malignant human tissues and in normal and damaged rat liver. In: Evans DMD, ed. Cytology automation. London and Edinburgh: Livingstone, 1970:108-20.

Requests for reprints to: Dr OAN Husain, Division of Pathology, Regional Cytology Centre, St Stephen's Hospital, Chelsea, London SW10 9TH, England. 